Research paper

\title{
Benznidazole microcrystal preparation by solvent change precipitation and in vivo evaluation in the treatment of Chagas disease
}

\author{
Flávia Pires Maximiano a , Lívia Maria de Paula ${ }^{a}$, Vivian Paulino Figueiredo ${ }^{\mathrm{b}}$, Isabel Mayer de Andrade ${ }^{\mathrm{b}}$, \\ André Talvani ${ }^{\mathrm{b}}$, Lívia C. Sá-Barreto ${ }^{\mathrm{c}}$, Maria Terezinha Bahia ${ }^{\mathrm{b}}$, Marcílio S.S. Cunha-Filho ${ }^{\mathrm{c}, *}$ \\ ${ }^{a}$ Escola de Farmácia, Universidade Federal de Ouro Preto (UFOP), Ouro Preto-MG, Brazil \\ b Instituto de Ciências Exatas e Biológicas, Universidade Federal de Ouro Preto (UFOP), Ouro Preto-MG, Brazil \\ ${ }^{\mathrm{c} I n s t i t u t o ~ d e ~ C i e ̂ n c i a s ~ d a ~ S a u ́ d e, ~ U n i v e r s i d a d e ~ F e d e r a l ~ d e ~ M a t o ~ G r o s s o ~(U F M T), ~ S i n o p-M T, ~ B r a z i l ~}$
}

\section{A R T I C L E I N F O}

Article history:

Received 22 November 2010

Accepted in revised form 3 March 2011

Available online 10 March 2011

\section{Keywords:}

Benznidazole

Chagas disease

Solvent change precipitation

Dissolution rate

Microcrystals

\begin{abstract}
A B S T R A C T
Benznidazole (BNZ) is traditionally used to treat Chagas disease. Despite its common use, BNZ has a poor water solubility and a variable bioavailability. The purpose of this study was to prepare BNZ microcrystals by solvent change precipitation and to study the effects of BNZ micronisation on therapeutic efficiency using a murine model of Chagas disease. The solvent change precipitation procedure was optimised in order to obtain stable and homogeneous particles with a small particle size, high yield and fast dissolution rate. The thermal and crystallographic analysis showed no polymorphic change in the microcrystals, and microscopy confirmed a significant reduction in particle size. A marked improvement in the drug dissolution rate was observed for micronised BNZ particles and BNZ tablets in comparison with untreated BNZ and commercial Rochagan ${ }^{\circledR}$. In vivo studies showed a significant increase in the therapeutic efficacy of the BNZ microparticles, corroborating the dissolution results.
\end{abstract}

(c) 2011 Elsevier B.V. All rights reserved.

\section{Introduction}

Benznidazole (BNZ; N-benzyl-2-nitro-1-imidazole-acetamide) is used as the primary therapeutic agent for treating acute Chagas disease [1]. Although this compound can eliminate the symptoms associated with the acute phase and provides a satisfactory cure rate, it is much less effective in the chronic phase of the disease. Unfavourable pharmacokinetic properties, such as poor water solubility, short terminal half-life and limited tissue penetration, lead to irregular oral absorption and promote an erratic bioavailability $[2,3]$.

In order to develop a more effective treatment, some studies have focused on the development of novel methods to administer BNZ, however, without any clear improvement in its therapeutic effect $[4,5]$. Silva and collaborators developed a ruthenium benzidazole complex more soluble in water and with higher trypanocidal activity than the free molecule. The synthesis of this derivative is still in laboratorial scale and it has an unknown industrial feasibility [6]. A recent study presents the preparation of microparticles of BNZ using chitosan by the coacervation method providing an

\footnotetext{
* Corresponding author. Instituto de Ciências da Saúde, Campus Universitário de Sinop, Universidade Federal de Mato Grosso (UFMT), Avenida Alexandre Ferronato, 1200, Reserva 35, Setor Industrial, 78557-267 Sinop-MT, Brazil. Tel.: +55 66 35317679; fax: +55 6635319797.

E-mail address: marciliofarm@hotmail.com (M.S.S. Cunha-Filho).
}

increase in dissolution rate of drug but without any in vivo testing [7].

The limited oral bioavailability of poor water-soluble drugs such as a BNZ is often related to the dissolution rate in the gastro-intestinal tract, which limits drug absorption [8]. Thus, novel methods to enhance drug dissolution are needed. Several techniques exist to improve the drug dissolution profile, such as reducing the particle size, which increases the surface area [9].

Physical methods, such as milling and grinding, are common ways to reduce the particle size $[10,11]$. However, these mechanical processes have several disadvantages. Oftentimes, particle size uniformity is not achieved due to the large energy input. In addition, disruption of the crystal lattice can cause physical or chemical instability. Furthermore, micronised powders with a higher energetic surface have a poor flow property and a broad size distribution, producing agglomerates with unfavourable solubility properties [9].

To overcome these problems, some recently developed techniques based on naturally grown crystals have been used to reduce particle size [12]. Briefly, drug powder is directly prepared in the micronised state during particle formation without any mechanical size reduction. Microcrystallisation of drugs is archived by a solvent change process that precipitates the drug in the presence of excipients, which cover the particle surface, to inhibit particle growth [13]. This approach is more advantageous than traditional milling techniques because the particle size is more uniform and the powder is less cohesive [14]. 
Therefore, the aim of this study was to prepare and characterise BNZ microcrystals produced by the solvent change method and to evaluate the therapeutic efficacy of fast-dissolving tablets produced with micronised BNZ in vivo.

\section{Materials and methods}

\subsection{Materials}

BNZ powder (lot 13,871; 99\% purity) and commercial tablets Rochagan ${ }^{\circledR}$ were obtained from Roche ${ }^{\circledR}$ (Basel, Switzerland).

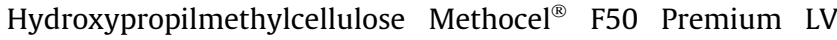
(F50), Hydroxypropilmethylcellulose Methocel $^{\circledR}$ K100 Premium LV (K100), Hydroxypropilmethylcellulose Methocel $^{\circledR}$ E10m Premium LV (E10m) and Starch $1500^{\circledR}$ were furnished by Colorcon ${ }^{\circledR}$ (Cotia, Brazil). Hydroxyethylcellulose Cellosize ${ }^{\circledR}$ QP 300 (HEC) was supplied by Polytechno ${ }^{\circledR}$ (São Paulo, Brazil). Magnesium stearate, polyethylene glycol 4000 Carbovaw $^{\circledR}$ (PEG) and sodium lauryl sulphate (SLS) were obtained from Vetec ${ }^{\circledR}$ (Duque de Caxias, Brazil). All solvents were of analytical grade.

\subsection{Solvent change precipitation procedure}

\subsubsection{Preliminary investigation}

BNZ micronisation was performed using the solvent change method by instantaneously mixing two liquids in the presence of a stabilizing agent, as described by Gassmann and co-workers [15]. Briefly, the drug was dissolved close to the saturation concentration in an organic solvent that is miscible with water. A stabilizing agent was dissolved in water. The aqueous solution was poured rapidly from a beaker into the drug solution with constant stirring. The BNZ microsuspension was filtered through a nylon membrane $(0.45 \mu \mathrm{m})$ and dried in an oven at $37^{\circ} \mathrm{C}$ for $24 \mathrm{~h}$.

Preliminary studies were performed to determine the ideal conditions for the preparation of microcrystals using the solvent change method. The effects of experimental variables on microcrystal yield and particle dissolution rate were determined.

Particle stability and the particle's physical properties are dependent on the stabilizer used [9]. Several stabilizers with a hydrophilic structure were investigated (F50, K100, E10m, PEG and $H E C$ ), and the BNZ particles produced from them were designated, $\mathrm{BNZ}_{\mathrm{F} 50}, \mathrm{BNZ}_{\mathrm{K} 100}, \mathrm{BNZ}_{\mathrm{E} 10 \mathrm{~m}}, \mathrm{BNZ} Z_{\mathrm{PEG}}$ and $\mathrm{BNZ}_{\mathrm{HEC}}$, respectively. The organic solvent was chosen based on the ability to dissolve BNZ and on the amount of precipitation obtained after phase change. The solvents tested were acetone, methanol and ethanol. The solution temperature during phase change was also evaluated; the experiment was performed at $5{ }^{\circ} \mathrm{C}$ and $25^{\circ} \mathrm{C}$. Four different solvent ratios (organic to water) were tested: 1:0.5, 1:1, 1:4 and 1:8. In each experiment, a high concentration of stabilizer was used $(0.1 \% \mathrm{w} / \mathrm{v})$ in order to not make this a limiting factor.

Finally, four different stabilizer concentrations $(0.005,0.05,0.01$ and $0.1 \% \mathrm{w} / \mathrm{v}$ ) were tested in order to estimate the minimum concentration of polymer necessary to obtain the soluble drug particle at a maximum yield. Each experiment was performed in triplicate.

After the preliminary studies, the optimised crystallisation method was used to produce a sufficient amount of micronised particle for the in vivo experiment. Approximately $50 \mathrm{~g}$ of micronised BNZ was prepared for each stabilizer. Production scale-up was performed fitting the crystallisation condition.

\subsection{Particle characterisation}

\subsubsection{Drug assay}

BNZ was quantified using a validated spectrophotometric method. A calibration curve was made using a standard solution of BNZ in the range of $8-28 \mu \mathrm{g} / \mathrm{mL}$ in water/methanol $(1: 1 \mathrm{v} / \mathrm{v})$ using an UV-visible spectrophotometer (He $\lambda$ ios $\alpha$ Thermo Electron Corporation ${ }^{\circledR}$ Waltham, USA) set to $324 \mathrm{~nm}$. No effect of polymers addition on the UV spectrum of BNZ was verified.

\subsubsection{Dissolution studies}

Dissolution studies were performed using sink conditions and the USP basket method (apparatus 1) using Nova Ética ${ }^{\circledR} 299$ dissolution equipment (Vargem Grande Paulista, Brazil). The rate of stirring was $75 \pm 2 \mathrm{rpm}$, and the temperature of the dissolution media was set to $37 \pm 1^{\circ} \mathrm{C}$. The dissolution medium $(900 \mathrm{~mL})$ was simulated gastric fluid $\mathrm{pH} 1.2$ [16]. BNZ samples of $50 \mathrm{mg}$ or an equivalent amount of each micronised system was placed in hard gelatin capsules and tested in triplicate.

At regular time intervals, suitable amount of sample medium was withdrawn and same amount replaced by fresh medium. Samples were diluted and filtered through a syringe filter $(0.45 \mu \mathrm{m})$. The concentration of dissolved drug in the medium was determined using a spectrophotometer set to $324 \mathrm{~nm}$. The dissolution profiles were compared using the dissolution efficiency at $20 \mathrm{~min}$ [17]. Statistical analysis of the dissolution efficiency was performed using a one-way analysis of variance (ANOVA) followed by least significant difference.

\subsubsection{Scanning electron microscopy (SEM)}

Scanning electron micrographs were taken using a JEOL JSM$5510^{\circledR}$ microscope (Westmont, USA) operating at $15 \mathrm{kV}$. Particles were fixed on a brass stub using a conductive double-sided adhesive tape and coated under vacuum with graphite in an argon atmosphere at $50 \mathrm{~mA}$ for $50 \mathrm{~s}$.

\subsubsection{Optical microscopy}

The particle surface morphology was examined using a TNB04D OPTON ${ }^{\circledR}$ (São Paulo, Brazil) microscope connected to a video camera.

\subsubsection{X-ray powder diffractometry (XRPD)}

X-ray powder diffractograms were obtained using a Shimadzu XRD 6000 diffractometer (Kyoto, Japan) equipped with an iron tube and a graphite monochromator. The scans were performed between $2^{\circ}$ and $60^{\circ}(2 \theta)$ with a scanning speed of $2^{\circ} \theta / \mathrm{min}$.

\subsubsection{Differential Scanning Calorimetry (DSC)}

Samples weighing $2-3 \mathrm{mg}$ were placed in aluminium crucible pans and heated from 25 to $250{ }^{\circ} \mathrm{C}$ at a rate of $10^{\circ} \mathrm{C} / \mathrm{min}$ using a DSC 2010 TA Instrument ${ }^{\circledR}$ (New Castle, USA). Gas was purged using nitrogen at a flux rate of $50 \mathrm{~mL} / \mathrm{min}$. The DSC instrument was calibrated using indium and zinc standards.

\subsubsection{Surface area}

Particle surface area was determined using gas adsorption, and the calculation was based on the BET equation [18]. Samples were degassed under a vacuum for $24 \mathrm{~h}$ at $40{ }^{\circ} \mathrm{C}$ and then analysed by a Surface Area Analyser Nova 1000 (Quantachrome Instruments ${ }^{\circledR}$, Boynton Beach, USA).

\subsubsection{Flow property study}

The flow properties of untreated and micronised samples were evaluated using the Carr index and pharmacopoeia parameters $[16,19]$. The angle of repose was assessed using the fixed funnel method [20]. Flow time was established by recording the time, and it took for a predetermined sample to flow through a standard funnel.

The compressibility index was determined using a density apparatus and was calculated by the following formula below: 
Compressibility index $=100 \times\left(\rho_{t}-\rho_{a}\right) / \rho_{t}$

where $\rho_{a}$ is the bulk density of material freely settled and $\rho_{t}$ is the maximum packing density of the material. Each experiment was performed in triplicate.

\subsection{Tablets manufacture}

BNZ micronised particles were incorporated into a final dosage form. Tablets (300 mg) were produced by compression previous dry granulation. Mixtures of selected micronised BNZ containing an amount equivalent to $100-\mathrm{mg}$ drug, $0.3 \%$ magnesium stearate and a sufficient amount of Starch $1500^{\circledR}$ were blended in a $\mathrm{V}$ mixer for $15 \mathrm{~min}$. Formulations were made with and without addition of $1 \%$ sodium lauryl sulphate (SLS) as a wetting agent. Batches containing $60 \mathrm{~g}$ of each formulation were compacted into slugs using an eccentric press Primel FABBE$^{\circledR}$ (São Paulo, Brazil) fitted with $16-\mathrm{mm}$ diameter flat punches. Slugs were crushed in an oscillating granulator, sieved through a $1.5-\mathrm{mm}$ filter and compressed using the tablet machine fitted with $10-\mathrm{mm}$ concave punches. Around 150 tablets were obtained from each batch.

$\mathrm{BNZ}_{\mathrm{HEC}}$ and $\mathrm{BNZ}_{\mathrm{PEG}}$ tablets without and with SLS were designated $\mathrm{T} 1_{\mathrm{HEC}}-\mathrm{T} 2_{\mathrm{HEC}}$ and $\mathrm{T} 1_{\mathrm{PEG}}-\mathrm{T} 2_{\mathrm{PEG}}$, respectively.

\subsection{Tablet quality control}

Tablet formulations were subjected to the following tests according to pharmacopoeia [16].

\subsubsection{Drug assay}

Tablet drug content was measured using the spectrophotometric method described above. Ten randomly selected tablets were crushed, and an amount equivalent to $100 \mathrm{mg}$ of drug was weighed, extracted with methanol and filtered through a 0.45$\mu \mathrm{m}$ membrane. The absorbance was measured at $324 \mathrm{~nm}$. This test was carried out in triplicate.

\subsubsection{Weight}

The weights of 20 tablets were determined individually, and the mean weight and coefficient of weight variation were calculated.

\subsubsection{Hardness}

The hardness of ten randomly selected tablets was determined using an OFF-TEC Galileo ${ }^{\circledR}$ apparatus (Sao Bernardo do Campo, Brazil). The mean hardness and coefficient of hardness variation were calculated.

\subsubsection{Friability}

Tablet friability was measured as the percentage of weight loss of 10 tablets tumbled in a friabilator Ética ${ }^{\circledR}$ (Vargem Grande Paulista, Brazil) at $100 \mathrm{rpm}$ during $5 \mathrm{~min}$.

\subsubsection{Disintegration time}

Disintegration time was measured in water at $37^{\circ} \mathrm{C}$ using an Ética $^{\circledR}$ (Vargem Grande Paulista, Brazil) disintegration tester according to USP specifications. Six randomly selected tablets were tested for each formulation.

\subsubsection{Dissolution}

Dissolution studies were performed as described previously using the USP paddle method (apparatus 2) for tablets.

\subsection{Pharmacological studies}

\subsubsection{Infection and treatment scheme}

Female Swiss mice (18-23 g) from the animal's facilities at the Universidade Federal de Ouro Preto, Minas Gerais State, Brazil were used in this study. All procedures and experimental protocols were conducted in accordance with the Brazilian School of Animal Experimentation (COBEA) guidelines for the use of animals in research.

Groups of six animals were inoculated with $5.0 \times 10^{3}$ trypomastigotes of the Trypanosoma cruzi Y strain. Three groups received a commercial benznidazole tablet $\left(\right.$ Rochagan $\left.^{\circledR}\right)$, and three others received the $\mathrm{T} 2_{\mathrm{HEC}}$ tablet formulation. For the treatment, three doses were selected: (i) $100 \mathrm{mg}$ per $\mathrm{kg}$ of body weight, dose previously standardized by Filardi and Brener for experimental Chagas disease treatment [21]; (ii) half of that standard dose and (iii) one-fourth of standard dose. An untreated group, which received only the drug vehicle, was used as negative control. Tablets formulations were crushed, suspended with $4 \%$ arabic gum and administered at the 4th day post-infection, for seven consecutive days by the oral route.

\subsubsection{Parasitological test}

Circulating parasites in the treated animals were evaluated during and up to 30th day post-treatment to determine the suppression and/or natural reactivation of the parasitemia. The parasitemia was detected by microscopically examining tail blood, and the number of parasites was estimated as described by Brener [22]. The mortality rate was expressed as the cumulative percentage of dead animals.

Data were statistically analysed using GraphPad Prism software (GraphPad Software ${ }^{\circledR}$, La Jolla, USA). Data were initially assessed by ANOVA when interactions were significant, and the Tukey post hoc test was performed to analyse differences between mean values.

\section{Results and discussion}

The stabilizers used in the present study act as crystal growth inhibitors. A stabilizing polymer covers the hydrophobic surfaces of the precipitated crystals, inducing steric hindrance to prevent crystal growth [23]. The first step in the optimisation of the solvent change precipitation procedure was to determine the best stabilizer in improving drug dissolution. As seen in Fig. 1, the drug dissolution rate increased in the presence of stabilizers compared

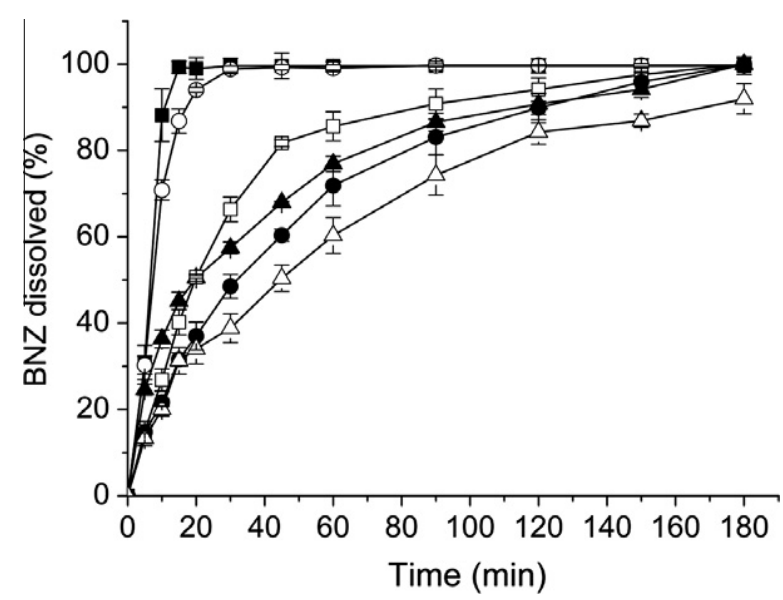

Fig. 1. Dissolution profiles of $(\Delta)$ untreated BNZ and micronised BNZ using different stabilizers prepared by solvent change method $(\bullet) \mathrm{BNZ}_{\mathrm{F} 50},(\square) \mathrm{BNZ}_{\mathrm{K} 100}$, (ム) $\mathrm{BNZ}_{\mathrm{E} 10 \mathrm{~m}},(\mathrm{O}) \mathrm{BNZ}$ PEG and (ם) BNZ $\mathrm{BEC}_{\mathrm{HEC}}$ in sink conditions. 
Table 1

Mean values of the dissolution efficiency at 20 min \pm standard deviation.

\begin{tabular}{ll}
\hline Sample & $\begin{array}{l}\text { Dissolution efficiency } \\
\text { at } 20 \mathrm{~min}(\%)\end{array}$ \\
\hline Powder & \\
BNZ $_{\text {untreated }}$ & $20.7 \pm 2.3$ \\
BNZ $_{\text {F50 }}$ & $21.4 \pm 3.1$ \\
BNZ $_{\text {K100 }}$ & $26.8 \pm 1.3$ \\
BNZ $_{\text {E10m }}$ & $32.8 \pm 2.5$ \\
BNZ $_{\text {HEC }}$ & $66.6 \pm 0.3$ \\
BNZ $_{\text {PEG }}$ & $60.9 \pm 0.9$ \\
Tablet & \\
Rochagan $^{\circledR}$ & $31.1 \pm 5.1$ \\
T1 $_{\text {HEC }}$ & $71.7 \pm 0.6$ \\
T2 $_{\text {HEC }}$ & $75.3 \pm 0.6$ \\
1 $_{\text {PEG }}$ & $74.2 \pm 0.4$ \\
2 $_{\text {PEG }}$ & $75.3 \pm 1.2$ \\
\hline
\end{tabular}

with untreated BNZ. The results showed that the type of stabilizer is important for the dissolution behaviour of micronised drug.

There were significant $(p<0.05)$ differences in the dissolution efficiency at $20 \mathrm{~min}$ (Table 1 ) between each of the micronised samples, except for the $\mathrm{BNZ}_{\mathrm{F} 50}$ particles, which had a similar dissolution profile in comparison with untreated BNZ. The HEC and PEG stabilizers dramatically enhanced the drug dissolution rate with almost $100 \%$ drug dissolved at 10 min (Fig. 1). Thus, HEC and PEG were selected for next sequence of experiments.
Fig. 2 shows the results of the remaining methodology parameters in the solvent change method. In brief, we found that acetone was the optimal solvent to precipitate crystals, with over a $90 \%$ yield for both polymers. Maximum crystal yield was obtained at solvent ratio acetone/water of 1:1 and 1:4 (Fig. 2). However, during scale-up the $1: 1$ ratio did not promote drug crystallisation. Therefore, the 1:4 ratio was chosen to crystallise BNZ. The 1:0.5 ratio entailed a slight efficient polarity change because the aqueous phase was insufficient to induce crystallisation from the organic solvent, whereas a 1:8 ratio had a large aqueous phase volume that solubilised the BNZ.

Significant differences in the crystal yield were not observed with different temperatures during drug crystallisation (Fig. 2). Room temperature $\left(25^{\circ} \mathrm{C}\right)$ was selected for crystal production. With regard to the crystal yield and the dissolution efficiency at $20 \mathrm{~min}$, the optimal polymer concentration was $0.1 \%$ (Fig. 2). Below this concentration, particle growth occurred. In fact, a $0.01 \%$ concentration produced particles with a slow dissolution profile.

Finally, in the optimised crystallisation condition, the aqueous solution containing the stabilizers PEG or HEC $(0.1 \% \mathrm{w} / \mathrm{v})$ were poured into a BNZ acetone solution $(25 \mathrm{mg} / \mathrm{mL})$ using the $1: 4$ ratio (organic/water) with constant stirring at room temperature for approximately $2 \mathrm{~min}$.

The resulting drug load in the dried powder was approximately $100 \%$ for $\mathrm{BNZ}_{\mathrm{HEC}}$ and $\mathrm{BNZ}_{\mathrm{PEG}}$. No residual solvent remained in the samples, and the polymer was present only as a fine covering of microparticles at an insignificant amount. Similar results using this technique have been previously described [24,25].
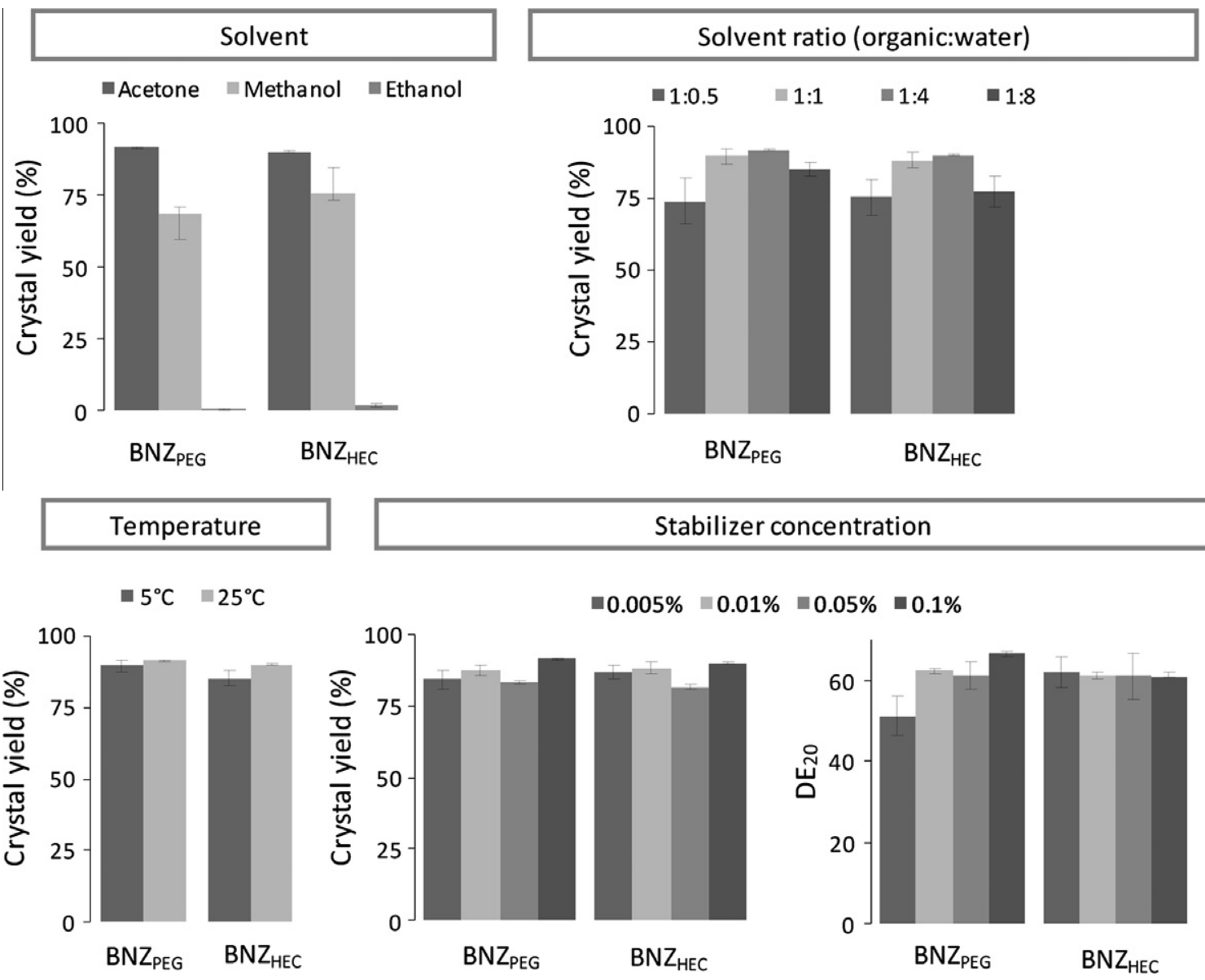

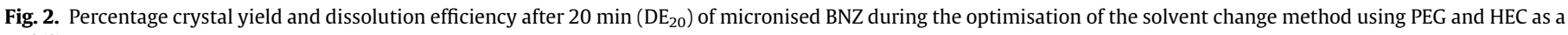
stabilizer. 
Polymorph and/or pseudopolymorph recrystallised products are sometimes obtained using solvent change precipitation, which affect drug quality and efficacy [26]. The BNZ $Z_{\mathrm{PEG}}$ and $\mathrm{BNZ} \mathrm{HEC}_{\mathrm{H}}$ recrystallised products were characterised by DSC and XRPD to determine the crystalline structure of BNZ.

Fig. 3 shows the DSC curves of untreated BNZ and its microcrystals as well as the thermal profiles of the PEG and HEC polymers. The common BNZ crystal has a sharp endotherm at $192{ }^{\circ} \mathrm{C}$ due its melting with an enthalpy of $153 \mathrm{~J} / \mathrm{g}$. According to Fig. 3, no unexpected event took place in micronised sample without changes in the melting peak of the drug. The stabilizer was not found in the micronised BNZ, indicating a high drug load.

As shown in Fig. 4, the XRPD pattern of micronised BNZ ${ }_{\mathrm{PEG}}$ and $B N Z_{\text {HEC }}$ was similar to that of the untreated drug. The main peaks of original drug at diffraction angles of 9.3, 13.7, 18.6, 21.1 and $27.6^{\circ} 2 \theta$ were present; however, differences in the relative peak

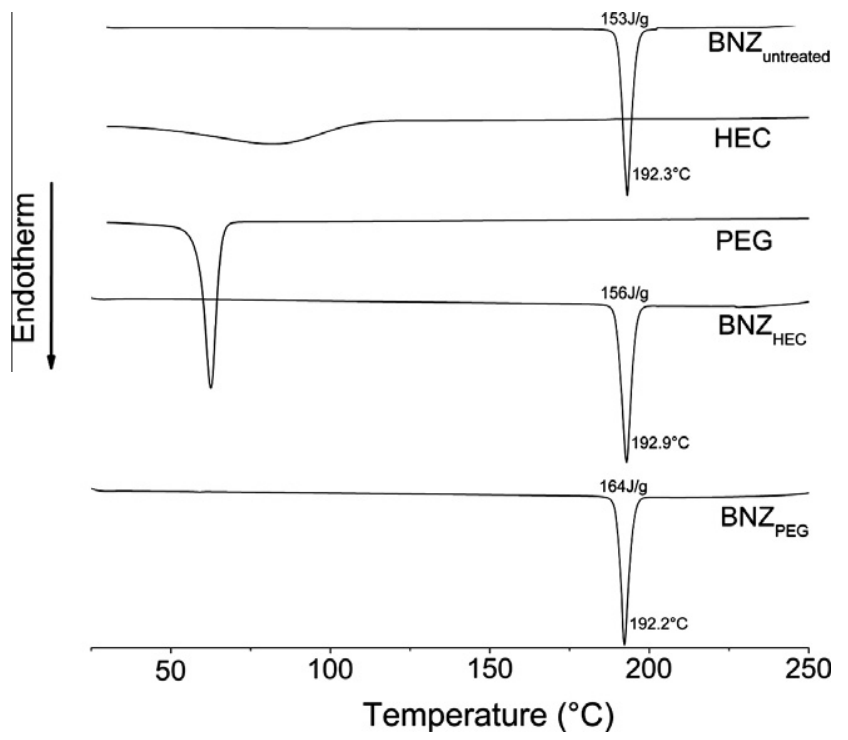

Fig. 3. DSC analysis of untreated BNZ, HEC, PEG and micronised $B N Z_{P E G}$ and $B N Z_{\text {HEC }}$ prepared by the solvent change method.

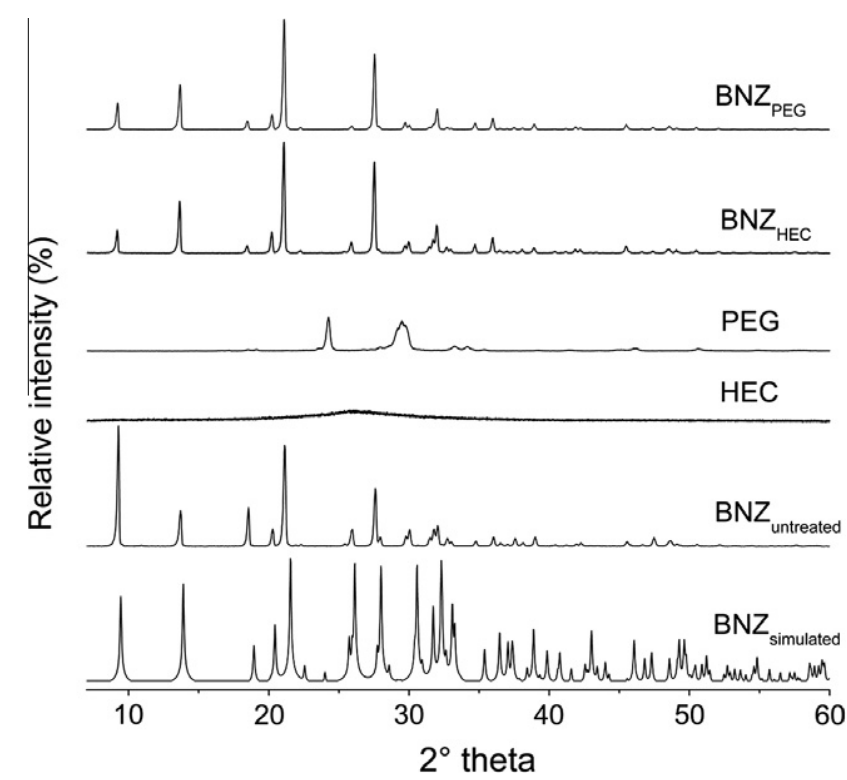

Fig. 4. XRPD of untreated $B N Z, H E C, P E G$ and micronised $B N Z_{P E G}$ and $B N Z_{H E C}$ prepared by the solvent change method. intensity can be appreciated. Apparently, slightly changes in the range of $30-50^{\circ} 2 \theta$ were observed. The samples were compared with the BNZ simulated pattern obtained from the single crystal data allowed to state that both $\mathrm{BNZ}_{\mathrm{PEG}}$ and $\mathrm{BNZ}_{\mathrm{HEC}}$ crystals are not new crystalline entities, but keep the same monoclinic crystallinity phase of untreated BNZ [27].

The peak height may be affected by crystal size and crystallinity. Therefore, the preferred orientation of crystals, dependent on size and crystalline growth, can explain the variation in relative peak intensity of the recrystallised BNZ. In addition, the diffractograms indicated that polymers were not detectable in the micronised samples. Thus, we conclude that precipitated drug was isomorphic with the initial crystal of BNZ, as indicated by DSC and XRPD analysis.

Optical microscopy and SEM microphotographs of untreated BNZ and micronised $B N Z_{P E G}$ and $B N Z_{H E C}$ are presented in Fig. 5. The BNZ microcrystals were homogeneous acicular crystals with a similar shape as the initial BNZ particle but had a significantly smaller size and thickness.

The $B_{\text {NEC }}$ surface area was approximately $1.1 \mathrm{~m}^{2} / \mathrm{g}$, whereas untreated BNZ had a surface area of $0.5 \mathrm{~m}^{2} / \mathrm{g}$. This increase in surface area as well as the reduction in particle size may account for its fast dissolution profile [9]. However, the micronised $B N Z_{P E G}$ had the same surface area as the initial crystal $\left(0.5 \mathrm{~m}^{2} / \mathrm{g}\right)$. This result might have been influenced by the agglomerate state of $B N Z_{P E G}$ powder. The increased drug dissolution rate in this sample may be related to the improved wetting properties of drug particles induced by the stabilizer, which decreases the interfacial tension between the dissolution medium and the drug [14].

The flow properties of untreated BNZ and micronised BNZ ${ }_{\mathrm{PEG}}$ and $\mathrm{BNZ}_{\mathrm{HEC}}$ in powder and in granulate form are presented in Table 2. Pure BNZ drug exhibited deficient flowability and compressibility as indicated by a high compressibility index, flow time and angle of repose. The micronised particles obtained by solvent change precipitation had an even more cohesive behaviour and, in concert with its low density, made it impossible to obtain tablets by direct compression. Dry granulation was used to increase the density and to improve the particle's rheological properties without changing its surface characteristics [25]. As expected, the granulate process using pharmaceutical excipients produced particles with better flow properties and bulk density, especially samples containing $\mathrm{BNZ}_{\mathrm{HEC}}$ (Table 2).

The weight, hardness, disintegration time, friability and drug assay of the tablet formulations are shown in Table 3. Tablets containing $\mathrm{BNZ}_{\mathrm{HEC}}$ met the pharmacopoeia quality specifications. However, formulations containing BNZ $\mathrm{PEG}_{\mathrm{PE}}$ showed difficulties to fill the dies during the compression process. For this, the $\mathrm{T} 2_{\mathrm{PEG}}$ weight was out of range predefined, and the $\mathrm{T} 1_{\mathrm{PEG}}$ lacked content uniformity.

With regard to the drug dissolution profile (Fig. 6), the tablets containing BNZ microparticles had a fast dissolution behaviour, similar to the microcrystalline powders ( $\mathrm{BNZ}_{\mathrm{PEG}}$ and $\mathrm{BNZ}_{\mathrm{HEC}}$ ). The compression process did not interfere with the excellent dissolution behaviour of the BNZ particles obtained by solvent change precipitation. Moreover, the tablet formulations increased the drug dissolution efficiency at 20 min in comparison with the micronised particles alone (Table 1 ). The fast disintegration time of tablets together with its excellent wetting properties assigned to the excipients, like starch 1500, are some of the reasons for this outstanding dissolution behaviour [28].

The BNZ micronised tablet formulations dissolved $85 \%$ of the drug in the first $10 \mathrm{~min}$. However, the commercial BNZ tablet Roch$\operatorname{agan}^{\circledR}$ had a much lower dissolution rate. No more than $60 \%$ of the drug was dissolved after $60 \mathrm{~min}$ using these tablets. These results did not meet the US Food and Drug Administration specifications for immediate release solid oral dosage forms [29]. 

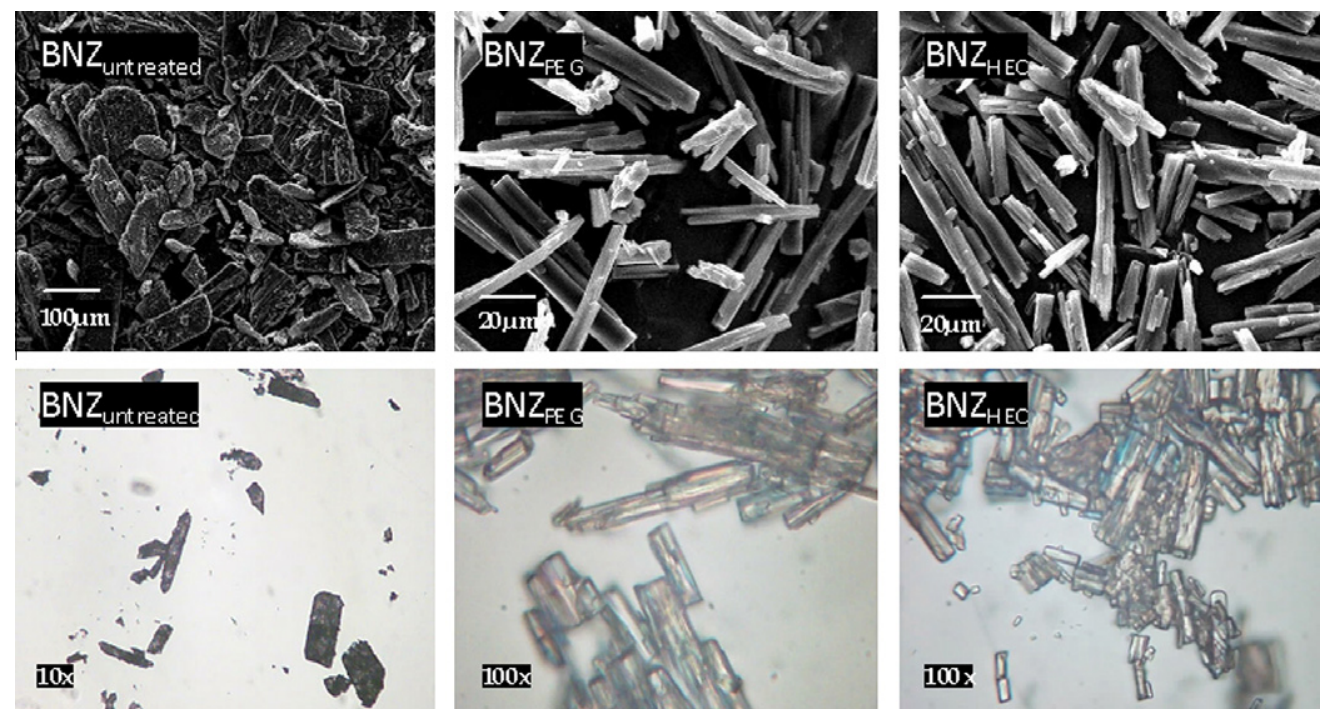

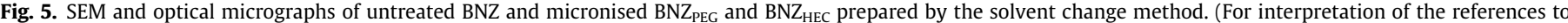
colour in this figure legend, the reader is referred to the web version of this article.)

Table 2

Flow property of BNZ untreated, micronized particles $\mathrm{BNZ}_{\mathrm{PEG}}$ and $\mathrm{BNZ}_{\mathrm{HEC}}$ and the granulates prepared from them.

\begin{tabular}{lllll}
\hline Sample & $\begin{array}{l}\text { Flow } \\
\text { time }(\mathrm{s})\end{array}$ & $\begin{array}{l}\text { Angle of } \\
\text { repose }\left(^{\circ}\right)\end{array}$ & $\begin{array}{l}\text { Compressibility } \\
\text { index }(\%)\end{array}$ & $\begin{array}{l}\text { Bulk density } \\
(\mathrm{g} / \mathrm{mL})\end{array}$ \\
\hline Powder & & & & \\
BNZ $_{\text {untreated }}$ & $\infty$ & 60.0 & 40.7 & 0.39 \\
BNZ $_{\text {HEC }}$ & $\infty$ & 58.3 & 60.6 & 0.15 \\
BNZ $_{\text {PEG }}$ & $\infty$ & 60.0 & 56.0 & 0.20 \\
Granulate & & & & \\
T1 $_{\text {HEC }}$ & 3.6 & 43.0 & 25.3 & 0.58 \\
T2 $_{\text {HEC }}$ & 3.8 & 36.7 & 21.7 & 0.58 \\
T1 $_{\text {PEG }}$ & 3.6 & 35.7 & 27.8 & 0.56 \\
T2 & & 38.3 & 30.9 & 0.56 \\
\hline
\end{tabular}

Incorporation of the surfactant SLS into the tablet formulation did not influence the dissolution process of the $B N Z_{P E G}$ tablet. However, SLS did have a favourable effect on the BNZ $\mathrm{HEC}_{\mathrm{H}}$ tablets (Table 1 ) by improving wettability.

Even though the four tablet formulations had a similar dissolution behaviour, the $\mathrm{T} 2{ }_{\mathrm{HEC}}$ had a reliable quality control and produced granulates with better flow properties. Thus, $\mathrm{T} 22_{\mathrm{HEC}}$ was chosen for pharmacological tests.

Fig. 7 shows the parasitemia peak of infected mice treated with commercial Rochagan ${ }^{\circledR}$ or the $\mathrm{T} 2 \mathrm{HEC}_{\mathrm{HEC}}$ formulation containing BNZ microparticles. Each group treated with a dose of 100 and $50 \mathrm{mg} /$ $\mathrm{kg}$ had a significant diminution in the parasitemia peak in comparison with the control group. However, at $25 \mathrm{mg} / \mathrm{kg}$, only the $\mathrm{T}_{\mathrm{HEC}^{-}}$ treated mice had a significant decrease in parasitemia $(p<0.001)$.

As expected, there was a clear relation between dose and parasitemia level. Higher doses promoted a marked reduction in parasitemia. However, the decrease in parasitemia was more pronounced for the $\mathrm{T} 2{ }_{\mathrm{HEC}}$ tablets in comparison with Rochagan ${ }^{\circledR}$

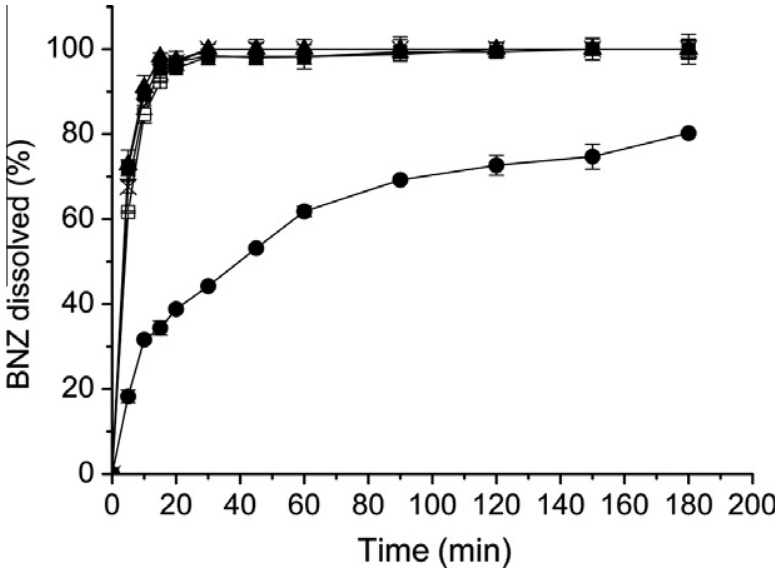

Fig. 6. Dissolution profiles of the $(\bullet)$ BNZ commercial tablet Rochagan ${ }^{\circledR}$ and tablets containing micronised BNZ prepared by the solvent change method (X) T1 $1_{\mathrm{PEG}},(\square)$ $\mathrm{T} 1_{\mathrm{HEC}},(\boldsymbol{\Lambda}) \mathrm{T}_{\mathrm{PEG}},(\mathbf{\square}) \mathrm{T} 2_{\mathrm{HEC}}$ in sink conditions.

at each dose studied. Additional biological parameters confirmed that $\mathrm{T} 2$ HEC gave a superior therapeutic response (Table 4).

Among the Rochagan-treated groups, only the $100 \mathrm{mg} / \mathrm{kg}$ dose was able to suppress parasitemia, whereas $\mathrm{T} 2_{\mathrm{HEC}}$ suppressed parasitemia in $100 \%$ of animals at a dose of 100 or $50 \mathrm{mg} / \mathrm{kg}$; the $25 \mathrm{mg} /$ $\mathrm{kg}$ dose suppressed $33 \%$ of the parasitemia (Table 4 ). The protocol adopted for this study with a short treatment (7 days) was not sufficient to promote the parasitological cure of animals. Therefore, the reactivation of parasitemia after initial suppression was expected. This procedure was useful to compare formulations and study dose-response relations.

The timing of parasitemia reactivation was dependent on the dose and formulation (Table 4). At $100 \mathrm{mg} / \mathrm{kg}$, Rochagan ${ }^{\circledR}$

Table 3

Quality control tablets containing micronized BNZ \pm standard deviation.

\begin{tabular}{|c|c|c|c|c|c|}
\hline Sample & Weight (\%) & Hardness (kgf) & Disintegration time (min) & Friability (\%) & Drug content (mg/tablet) \\
\hline $\mathrm{T} 1_{\text {HEC }}$ & $98.9 \pm 1.8$ & $9.5 \pm 2.5$ & 10.0 & 0.1 & $97.7 \pm 1.4$ \\
\hline $\mathrm{T} 2{ }_{\mathrm{HEC}}$ & $99.4 \pm 1.4$ & $3.3 \pm 0.8$ & 9.0 & 1.1 & $100.0 \pm 3.7$ \\
\hline $\mathrm{T} 1_{\mathrm{PEG}}$ & $100.6 \pm 1.3$ & $5.1 \pm 1.3$ & 10.0 & 0.2 & $104.7 \pm 16.9$ \\
\hline $\mathrm{T} 2_{\mathrm{PEG}}$ & $102.0 \pm 5.0$ & $3.1 \pm 0.7$ & 9.0 & 1.0 & $101.2 \pm 3.1$ \\
\hline
\end{tabular}




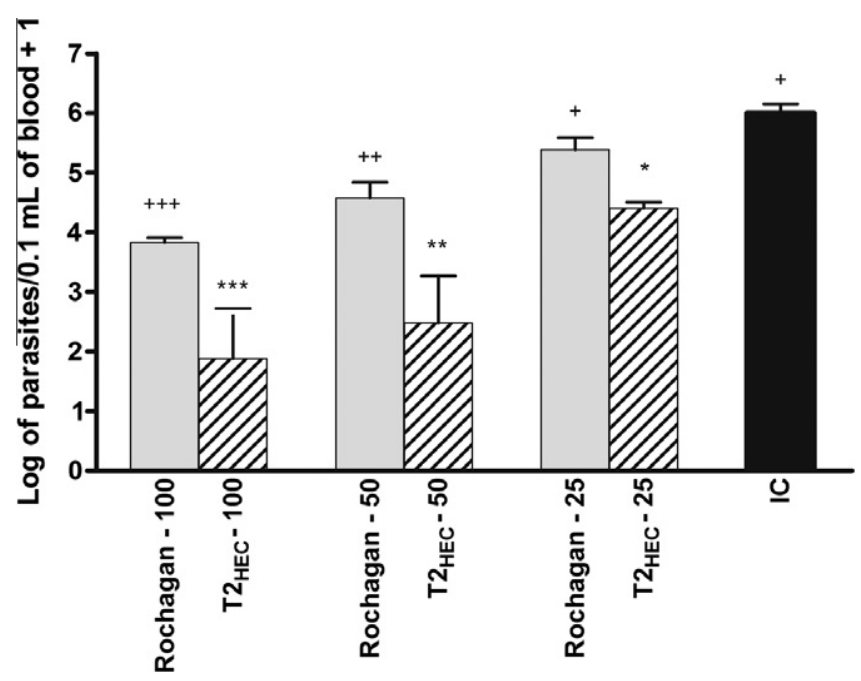

Fig. 7. Log of maximum number of blood trypomastigote forms from mice infected with the $5 \times 10^{3}$ trypomastigotes of Trypanosoma cruzi $\mathrm{Y}$ strain $(n=6)$ after treatment. Infected mice were grouped in untreated/control (IC) and in treated groups with 100,50 or $25 \mathrm{mg}$ of $\mathrm{T} 2_{\mathrm{HEC}}$ or Rochagan ${ }^{\circledR} /$ per $\mathrm{kg}$ of body weight for 7 days.

Table 4

Biological parameters evaluated in mice infected with Y T. cruzi strain and treated daily with 100,50 or $25 \mathrm{mg}$ of $\mathrm{T} 2_{\mathrm{HEC}}$ or Rochagan/per kg of body weight for 7 days

\begin{tabular}{llll}
\hline Groups $n=6$ & \multicolumn{2}{l}{ Evaluated parameters } \\
\cline { 2 - 4 } & $\begin{array}{l}\text { Clearance of } \\
\text { parasitemia } \\
\text { (Mice/total) }\end{array}$ & $\begin{array}{l}\text { Time of parasitemia } \\
\text { clearance (mean of time in } \\
\text { days } \pm \text { standard deviation) }\end{array}$ & $\begin{array}{l}\text { Mortality } \\
\text { (Mice/total) }\end{array}$ \\
\hline Rochagan-100 & $6 / 6(100 \%)$ & $10.3 \pm 6.0$ & $0 / 6$ \\
T2 HEC -100 & $6 / 6(100 \%)$ & $22.0 \pm 9.2$ & $0 / 6$ \\
Rocahgan-50 & $0 / 6(0 \%)$ & $\mathrm{ND}^{\mathrm{a}}$ & $1 / 6$ \\
T2 ${ }_{\mathrm{HEC}}-50$ & $6 / 6(100 \%)$ & $13.7 \pm 12.8$ & $0 / 6$ \\
Rochagan-25 & $0 / 6(0 \%)$ & $\mathrm{ND}^{\mathrm{a}}$ & $2 / 6$ \\
T2 $2_{\mathrm{HEC}}-25$ & $2 / 6(33 \%)$ & $1.5 \pm 0.7$ & $0 / 6$ \\
Untreated control & - & - & $6 / 6(100 \%)$ \\
\hline
\end{tabular}

a $\mathrm{ND}=$ not detected.

suppressed parasitemia reactivation for 10 days, whereas the micronised BNZ T2 $2_{\mathrm{HEC}}$ achieved suppression for nearly 22 days. In addition, after treatment with $50-\mathrm{mg} / \mathrm{kg} \mathrm{T} 2_{\mathrm{HEC}}$, reactivation of parasitemia was observed at 13 days.

The $\mathrm{T} 2_{\mathrm{HEC}}$ treatment had superior effects on mortality. Whereas $100-\mathrm{mg} / \mathrm{kg}$ Rochagan ${ }^{\circledR}$ was needed to prevent animal death, the $\mathrm{T} 2_{\text {HEC }}$ tablets achieved $100 \%$ survival at every dose tested (Table 4 ).

These results suggest that the BNZ bioavailability was enhanced by the solvent change precipitation method. Additional studies using a complete treatment cycle for parasitological cure of animals are now being performed.

\section{Conclusions}

The results of the present study demonstrate that solvent change precipitation can be used to produce BNZ microparticles, avoiding critical effects resulting from milling processes. The optimised method conditions were performed in order to produce micron-sized BNZ particles with a high crystal yield and a fast dissolution rate. This technique offers a relatively easy way for the production of micronised drugs in one-process step using only ordinary equipment. The tablet produced from BNZ microparticles showed markedly enhanced drug dissolution rate, compared with the untreated BNZ crystal and with commercial Rochagan ${ }^{\circledR}$. The in vivo studies showed important progresses in the therapeutic performance of BNZ microparticles, corroborating previous dissolution results and suggesting an improvement in the bioavailability of the drug.

\section{Acknowledgements}

The authors would like to thank LAFEPE, Brazil and Professor José Lamartine Soares Sobrinho, Universidade Federal do Piauí, Brazil, for their charitable donation of the BNZ. This work was supported by CNPq (Brazil; Project No. 472134/2008-6). The authors are also thankful for generous gift of diluent samples from Colorcon, Brazil.

\section{References}

[1] J.R. Coura, S.L. de Castro, A critical review on Chagas disease chemotherapy, Mem. Inst. Oswaldo Cruz. 97 (2002) 3-24.

[2] I.S. Caldas, A. Talvani, S. Caldas, C.M. Carneiro, M. de Lana, P.M. da Matta Guedes, M.T. Bahia, Benznidazole therapy during acute phase of Chagas disease reduces parasite load but does not prevent chronic cardiac lesions, Parasitol. Res. 103 (2008) 413-421.

[3] J.A. Urbina, Ergosterol biosynthesis and drug development for Chagas disease, Mem. Inst. Oswaldo Cruz. 104 (2009) 311-318.

[4] M.J. Morilla, J.A. Montanari, M.J. Prieto, M.O. Lopez, P.B. Petray, E.L. Romero, Intravenous liposomal benznidazole as trypanocidal agent: increasing drug delivery to liver is not enough, Inter. J. Pharm. 278 (2004) 311-318.

[5] M. Lamas, L. Villaggi, I. Nocito, G. Bassani, D. Leonardi, F. Pascutti, E. Serra, C.J. Salomon, Development of parenteral formulations and evaluation of the biological activity of thetrypanocide drug benznidazole, Inter. J. Pharm. 307 (2006) 239-243.

[6] J.J.N. Silva, W.R. Pavanelli, F.R.S. Gutierrez, F.C.A. Lima, A.B.F. Silva, J.S. Silva, D.W. Franco, Complexation of the anti-Trypanosoma cruzi drug benznidazole improves solubility and efficacy, J. Med. Chem. 51 (2008) 4104-4114.

[7] D. Leonardi et al., Development of novel formulations for Chagas' disease: optimization of benznidazole chitosan microparticles based on artificial neural networks, Inter. J. Pharm. 367 (2009) 140-147.

[8] R. Lobenberg, G.L. Amidon, Modern bioavailability, bioequivalence and biopharmaceutics classification system. New scientific approaches to international regulatory standards, Eur. J. Pharm. Biopharm. 50 (2000) 3-12.

[9] N. Rasenack, B.W. Muller, Dissolution rate enhancement by in situ micronization of poorly water-soluble drugs, Pharm. Res. 19 (2002) 18941900.

[10] A. Rajeev, L.B. Jain, J.A. Strauba, T. Tessiera, H. Bernsteina, Effect of powder processing on performance of fenofibrate formulations, Eur. J. Pharm. Biopharm. 69 (2008) 727-734.

[11] S. Goto, Time-dependence of particle size during comminution and a scale-up procedure for stirred media mills, Adv. Powder Technol. 21 (2010) 310-319.

[12] M. Sarkari, J. Brown, X. Chen, S. Swinnea, R.O. Williams, K.P. Johnston, Enhanced drug dissolution using evaporative precipitation into aqueous solution, Int. J. Pharm. 243 (2002) 17-31.

[13] R.A. Keraliy, T.G. Soni, V.T. Thakkar, T.R. Gandhi, R.C.P. Rajesh, Formulation and physical characterization of microcrystals for dissolution rate enhancement of tolbutamide, Int. J. Res. Pharm. Sci. 1 (2010) 69-77.

[14] R. Talari, J. Varshosaz, S.A. Mostafavi, A. Nokhodchi, Dissolution enhancement of gliclazide using $\mathrm{pH}$ change approach in presence of twelve stabilizers with various physico-chemical properties, J. Pharm. Pharm. Sci. 12 (2009) 250-265.

[15] P. Gassmann, M. List, A. Schweitzer, H. Sucker, Hidrosols - alternatives for the parenteral application of poorly water soluble drugs, Eur. J. Pharm. Biopharm. 40 (1994) 64-72.

[16] USP 30 United States Pharmacopeia, 30th ed. United States Pharmacopeial Convention, Rockville, 2008.

[17] K.A. Khan, C.T. Rhodes, Effect of compaction pressure on the dissolution efficiency of some direct compression systems, Pharm. Acta. Helv. 47 (1972) 594-607.

[18] N.G. Stanley-Wood, Enlargement and Compaction of Particle Solids, Butterworth, London, 1983.

[19] R.L. Carr, Evaluation of flow properties of solids, Chem. Eng. J. 72 (1965) 163168.

[20] M.E. Aulton, Aulton's Pharmaceutics: The Design and Manufacture of Medicines, third ed., Elsevier, London, 2007.

[21] L.S. Filardi, Z. Brener, Susceptibility and natural resistance of Trypanosoma cruzi strains to drugs used clinically in Chagas disease, Trans. Roy. Soc. Trop. Med. Hyg. 81 (1987) 755-759.

[22] Z. Brener, Therapeutic activity and criterion of cure on mice experimentally infected with Trypanosoma cruzi, Rev. Inst. Med. Trop. 4 (1962) 389-396. 
[23] R. Talari, J. Varshosaz, S.A. Mostafavi, A. Nokhodchi, Gliclazide microcrystals prepared by two methods of in situ micronization: pharmacokinetic studies in diabetic and normal rats, AAPS PharmSciTech. 11 (2010) 786-792.

[24] H. Steckel, N. Rasenack, B.W. Muller, In-situ-micronization of disodium cromoglycate for pulmonary delivery, Eur. J. Pharm. Biopharm. 55 (2003) 173-180.

[25] M.S.S. Cunha-Filho, R. Martinez-Pacheco, M. Landin, Dissolution rate enhancement of the novel antitumoral $\beta$-lapachone by solvent change precipitation of microparticles, Eur. J. Pharm. Biopharm. 69 (2008) 871-877.
[26] B.Y. Shekunov, P. York, Crystallization processes in pharmaceutical technology and drug delivery design. J. Cryst. Growth 211 (2000) 122-136.

[27] J.L. Soares-Sobrinho, M.S.S. Cunha-Filho, P.J. Rolim Neto, J.J. TorresLabandeira, B. Dacunha-Marinho, Benznidazole, Acta Cryst. E64 (2008) 0634.

[28] R.C. Rowe, P.J. Sheskey, M.E. Quinn, Handbook of Pharmaceutical Excipients, sixth ed., Pharmaceutical Press, London, 2009.

29] Food and Drug Administration (FDA). Guidance for Industry Dissolution Testing of Immediate Release Solid Oral Dosage Forms, 1997. 